\title{
Cytokine receptor signaling activates an IKK-dependent phosphorylation of PUMA to prevent cell death
}

\author{
JJ Sandow ${ }^{1,2,3,4,5}$, AM Jabbour ${ }^{3,4,6}$, MR Condina ${ }^{7}$, CP Daunt ${ }^{3,4}$, FC Stomski ${ }^{1}$, BD Green ${ }^{3,4,6}$, CD Riffkin ${ }^{3,4}$, P Hoffmann ${ }^{7}$, \\ MA Guthridge ${ }^{1}$, J Silke ${ }^{4,5,8}$, AF Lopez ${ }^{\star, 1,2}$ and PG Ekert ${ }^{\star, 3,4,5}$
}

P53-upregulated modifier of apoptosis (PUMA), a pro-apoptotic member of the Bcl-2 family, is transcriptionally activated by p53 and is a key effector of p53-dependent apoptosis. We show that PUMA protein is subject to rapid post-translational regulation by phosphorylation at a conserved residue, serine 10, following serum or interleukin-3 (IL-3) stimulation. Serine 10 is not within the $\mathrm{Bcl}-2$ homology $(\mathrm{BH} 3)$ domain, and PUMA phosphorylated at serine 10 retained the ability to co-immunoprecipitate with antiapoptotic $\mathrm{Bcl}-2$ family members. However, phosphorylated PUMA was targeted for proteasomal degradation indicating that it is less stable than unphosphorylated PUMA. Importantly, we identified IKK1/IKK2/Nemo as the kinase complex that interacts with and phosphorylates PUMA, thereby also demonstrating that IL-3 activates NFkB signaling. The identification and characterization of this novel survival pathway has important implications for IL-3 signaling and hematopoietic cell development. Cell Death and Differentiation (2012) 19, 633-641; doi:10.1038/cdd.2011.131; published online 14 October 2011

The pro-apoptotic functions of p53 depend critically on transcriptional upregulation of two members of the $\mathrm{Bcl}-2$ family, P53-upregulated modifier of apoptosis (PUMA) and NOXA. ${ }^{1,2}$ In addition to mediating p53-dependent apoptotic stimuli, PUMA is also required for the execution of p53independent death stimuli in thymocytes and is a regulator of the balance between apoptosis and survival in hematopoietic cells. ${ }^{2-5}$ PUMA and NOXA belong to the pro-apoptotic class of the $\mathrm{Bcl}-2$ proteins known as $\mathrm{Bcl}-2$ homology (BH3)-only proteins, which are characterized by the presence of a single $\mathrm{BH} 3$ domain. Pathophysiologically, PUMA functions as a tumor suppressor in murine models of lymphoma ${ }^{6}$ and PUMA expression is frequently silenced in pediatric leukemia. ${ }^{7}$

PUMA expression is lethal in many cell types because PUMA ubiquitously neutralizes antiapoptotic Bcl-2 family members. ${ }^{8}$ Dependent on the model system, PUMA may directly activate $\mathrm{Bax}^{9}$ or sensitize cells to Bax activation by other BH3-only proteins. ${ }^{10}$ Following cytokine deprivation, PUMA is upregulated and has a critical role in committing cells to apoptosis. interleukin-3 (IL-3)-dependent cells that have survived the IL-3 deprivation can proliferate again if IL-3 is restored, and deletion of PUMA greatly increased this population. ${ }^{11}$ This suggests that cells surviving cytokine deprivation have mechanisms, other than regulating PUMA transcription, to inactivate or clear the PUMA protein. It was recently shown that PUMA protein stability is, in part, regulated by the phosphorylation of PUMA on a specific residue, serine $10 .^{12}$ The stimuli causing PUMA phosphorylation and the kinase responsible remained unclear. Using mass spectroscopy, we had identified that serine 10 in PUMA was phosphorylated in response to IL-3 or serum stimulation after a period of deprivation. We generated an antibody that detected PUMA serine 10 phosphorylation to demonstrate phosphorylation of endogenous PUMA. Mutation of serine 10 prolonged the half-life of overexpressed PUMA, because mutation of serine 10 permits PUMA to escape proteasomal degradation. Importantly, this mechanism was dependent on the integrity of the IKappaB kinase (IKK) complex. Deletion of either IKK1/IKK $\alpha$ or IKK2/IKK 3 blocked serine 10 phosphorylation. Furthermore, IKK1 co-immunoprecipitated with PUMA and directly phosphorylated PUMA at serine 10 in vitro. When the IKK activity was inhibited, there was a loss of cell viability. Interestingly, the loss of viability from IKK inhibition could be attenuated by the genetic deletion of PUMA. These data provide compelling evidence that the IKK complex regulates cell survival by phosphorylating PUMA on serine 10 and targeting it for proteasomal degradation.

We propose a model in which PUMA protein, expressed in cells yet to commit to apoptosis following a sublethal period of

\footnotetext{
${ }^{1}$ Centre for Cancer Biology, Division of Human Immunology, SA Pathology, Adelaide, South Australia 5000, Australia; ${ }^{2}$ School of Medicine, Faculty of Health Sciences, University of Adelaide, Adelaide, South Australia 5005, Australia; ${ }^{3}$ Children's Cancer Centre, Murdoch Children's Research Institute, Royal Children's Hospital, Flemington Road, Parkville, Victoria 3052, Australia; ${ }^{4}$ The Walter and Eliza Hall Institute of Medical Research, 1G Royal Parade, Parkville, Victoria 3050, Australia; ${ }^{5}$ Department of Medical Biology, The University of Melbourne, Parkville, Victoria 3010, Australia; ${ }^{6}$ Department of Paediatrics, University of Melbourne, Royal Children's Hospital, Flemington Road, Parkville, Victoria 3052, Australia; ${ }^{7}$ Adelaide Proteomics Centre, School of Molecular and Biomedical Science, University of Adelaide, Adelaide, South Australia 5005, Australia and ${ }^{8}$ Department of Biochemistry, Latrobe University, Bundoora, Victoria 3083, Australia

${ }^{*}$ Corresponding authors: AF Lopez, Centre for Cancer Biology, Division of Human Immunology, SA Pathology, Adelaide, South Australia 5000, Australia.

Tel: + 6188222 3437; Fax: + 6188232 4092; E-mail: angel.lopez@health.sa.gov.au

or PG Ekert, Children's Cancer Centre, Murdoch Children's Research Institute, Royal Children's Hospital, Flemington Road, Parkville, Victoria 3052 , Australia.

Tel: + 6139345 2548; Fax: + 6139347 0852; E-mail: ekert@ wehi.edu.au

Keywords: PUMA; interleukin-3; post-translational; phosphorylation; degradation; IKK

Abbreviations: 4-OHT, 4-hydroxytamoxifen; $\mathrm{CHX}$, cycloheximide; FDM, factor-dependent myeloid; IKK, IkappaB kinase; IL-3, interleukin-3; MEF, murine embryonic fibroblast; PI, propidium iodide; PUMA, p53-upregulated modifier of apoptosis

Received 11.1.11; revised 17.8.11; accepted 05.9.11; Edited by JP Medema; published online 14.10.11
} 
cytokine or serum deprivation, is cleared by a process involving site-specific PUMA phosphorylation and proteasomal degradation. This is the first demonstration of IKKdependent post-translational regulation of PUMA following cytokine signaling. Our findings demonstrate that cytokines such as IL-3 activate IKK to repress apoptosis, implicating this novel pathway in the normal and pathophysiological regulatory control of hematopoietic cell survival.

\section{Results}

PUMA is phosphorylated in response to serum or IL-3 stimulation. To determine whether PUMA was posttranslationally modified by phosphorylation, we cultured HEK 293T cells transfected with HA-tagged human PUMA with ${ }^{32} \mathrm{P}$ orthophosphate and analyzed immunoprecipitated HA-PUMA (Figure 1a). Without serum, a small amount of ${ }^{32} \mathrm{P}$ was incorporated into PUMA. This increased over $15 \mathrm{~min}$ following serum re-addition and then declined (Figure 1a). We extended these observations by expressing HA-PUMA in HoxB8-transformed IL-3-dependent myeloid cells (factordependent myeloid (FDM) cells) lacking Bax and Bak, preventing overexpressed PUMA from inducing apoptosis. ${ }^{13}$ PUMA expression was under the control of a 4-hydroxytamoxifen (4-OHT)-inducible promoter. Following the IL-3 re-stimulation, ${ }^{32} \mathrm{P}$ incorporated into PUMA (Figure 1b). These data demonstrate time-dependent phosphorylation of overexpressed PUMA after the serum or IL-3 stimulation.

PUMA is phosphorylated at the serine 10 residue. To determine the site of PUMA phosphorylation, in-gel trypsinized HA-PUMA, enriched for phosphopeptides, was analyzed using LC-MS/MS in electron-transfer dissociation (ETD)/collision-induced dissociation (CID) mode. A peptide encompassing the PUMA serine 9 and 10 residues was phosphorylated. The presence of $\mathrm{c}_{6}$-ions at $646.2 \mathrm{~m} / \mathrm{z}, \mathrm{c}_{8}$-ion $910.4 \mathrm{~m} / \mathrm{z}, \mathrm{z}_{10}+1$-ion at $1118.5 \mathrm{~m} / \mathrm{z}$ and $\mathrm{z}_{11}+1$-ion at $1205.5 \mathrm{~m} / \mathrm{z}$ in the MS/MS ETD spectrum indicated that serine 10 was phosphorylated (Supplementary Figure 1). Alignment of PUMA N-terminal protein sequences demonstrated that serine 10 is conserved across numerous species and also appears to be conserved in another BH3-only protein, Bim (Supplementary Figure 2). This result identified serine 10 as a phosphorylation site although it does not absolutely exclude a low abundant peptide with serine 9 phosphorylated.

To confirm serine 10 phosphorylation, we mutated each serine residue to an alanine (PUMA ${ }^{\mathrm{S1OA}}, \mathrm{PUMA}^{\mathrm{S9A}}$ ) and expressed these in serum-stimulated HEK 293T cells in the presence of ${ }^{32} \mathrm{P}$ orthophosphate. Autoradiography identified ${ }^{32} \mathrm{P}$ incorporation into immunoprecipitated HA-PUMA (Figure 2a). Consistent with the LC-MS/MS results, serumstimulated cells expressing wild type and PUMA ${ }^{\text {S9A }}$, but not $\mathrm{PUMA}^{\mathrm{S} 10 \mathrm{~A}}$, were metabolically labeled with ${ }^{32} \mathrm{P}$. This experiment was repeated using IL-3-stimulated $\mathrm{Bax}^{-/-} ; \mathrm{Bak}^{-/-} \mathrm{FDM}$ cells. Two ${ }^{32} \mathrm{P}$-labeled bands were observed after IL-3 stimulation, one of which was serine 10 phosphorylation (Figure $2 \mathrm{~b}$ ), whereas only a single antiHA band was detected by western blot. There are several possibilities to account for

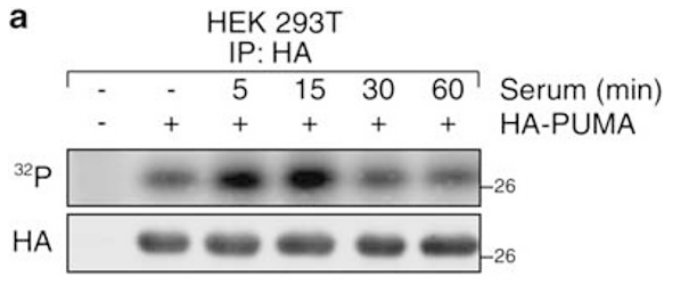

b

FDM Bax ; Bak IP: $\mathrm{HA}$

\begin{tabular}{|c|c|c|c|c|c|c|}
\hline \multicolumn{6}{|c|}{ IP: HA } & \\
\hline 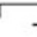 & - & 5 & 15 & 30 & 60 & IL-3 (min) \\
\hline . & + & + & + & + & + & 4-OHT \\
\hline & 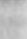 & 4 & $\pi$ & w & $\psi$ & -26 \\
\hline
\end{tabular}

Figure 1 Serum and IL-3 stimulation promotes phosphorylation of PUMA. (a) HA-PUMA was overexpressed in HEK 293T cells $16 \mathrm{~h}$ before starving the cells of serum and phosphate for $24 \mathrm{~h}$. Cells were metabolically labeled with $250 \mu \mathrm{Ci}^{32} \mathrm{P}$ orthophosphate for $4 \mathrm{~h}$ before stimulation with serum for the indicated periods of time. HA-PUMA was immunoprecipitated using an antiHA antibody, resolved by SDS-PAGE and either immunoblotted using antiHA antibody or exposed to $x$-ray film. (b) $\mathrm{Bax}^{-1-} ; \mathrm{Bak}^{-/-} \mathrm{FDM}$ cells were infected with a lentivirus encoding HA-PUMA under a 4-hydroxy tamoxifen (4-OHT)-inducible promoter. HA-PUMA protein expression was induced using $100 \mathrm{nM} 4-\mathrm{OHT}$ for $16 \mathrm{~h}$ before starving cells of IL-3 and phosphate for $24 \mathrm{~h}$. Cells were then metabolically labeled with $250 \mu \mathrm{Ci}{ }^{32} \mathrm{P}$ orthophosphate for $4 \mathrm{~h}$ before stimulation with $8 \mathrm{ng} / \mathrm{ml} \mathrm{IL-3}$ for the indicated period of time. HA-PUMA was immunoprecipitated using an antiHA antibody, resolved by SDS-PAGE and then either immunoblotted using antiHA antibody or exposed to X-ray film

a

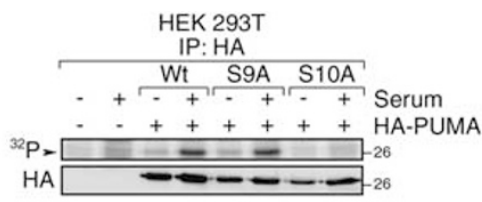

b

\begin{tabular}{|c|c|c|c|c|c|c|c|c|}
\hline \multicolumn{8}{|c|}{$\begin{array}{c}\text { FDM Bax } ; \mathrm{Bak}^{\prime} \\
\text { IP:HA }\end{array}$} & \\
\hline & \multicolumn{4}{|c|}{ HA-PUMA } & \multicolumn{3}{|c|}{ HA-PUMA ${ }^{S 10 A}$} & \\
\hline & 1 & 530 & 001 & 1530 & 0 & 1530 & $\begin{array}{lll}0 & 15 & 30\end{array}$ & IL-3 (min) \\
\hline & - & - & + & ++ & - & $\cdot \cdot+$ & & 4-OHT \\
\hline & & 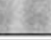 & $y=1$ & as & E & 8 & 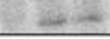 & -26 \\
\hline & & & -。 & -- & $=$ & - & $\cdots-\infty$ & -26 \\
\hline
\end{tabular}

Figure 2 Mutation of PUMA serine 10 inhibits phosphorylation of PUMA in response to serum and IL-3 signaling. (a) HA-PUMA wild type, HA-PUMA ${ }^{S 9 A}$ or HA-PUMA ${ }^{S 10 A}$ were expressed in HEK 293T cells for $16 \mathrm{~h}$ before removing serum and phosphate from the culture media for $4 \mathrm{~h}$. Cells were then metabolically labeled with ${ }^{32} \mathrm{P}$ orthophosphate for $4 \mathrm{~h}$ before serum stimulation for $15 \mathrm{~min}$. PUMA was immunoprecipitated using an antiHA antibody, resolved by SDS-PAGE and then either immunoblotted using antiHA antibody or exposed to x-ray film. Arrow indicates position of band corresponding to phosphorylated PUMA. (b) Bax ${ }^{-/}$; $\mathrm{Bak}^{-1-}$ FDM cells were infected with lentivirus encoding HA-PUMA wild type or HA-PUMA ${ }^{S 10 A}$ under a 4-OHT-inducible promoter. PUMA expression was induced using $100 \mathrm{nM} 4-\mathrm{OHT} 16 \mathrm{~h}$ before IL-3 and phosphate was removed from the culture media for $24 \mathrm{~h}$. Cells were then metabolically labeled with ${ }^{32} \mathrm{P}$ orthophosphate for $4 \mathrm{~h}$ before stimulation with IL-3 at $8 \mathrm{ng} / \mathrm{ml}$ for the indicated period of time. Immunoprecipitated HA-PUMA was visualized as described in (a)

the lower ${ }^{32} \mathrm{P}$-labeled band in FDM cells. It may be another form of phosphorylated PUMA not identified by the LC-MS/ MS, as serines 96 and 106 in PUMA are potential phosphorylation sites. ${ }^{12}$ Alternatively, it may be a non-specific protein 


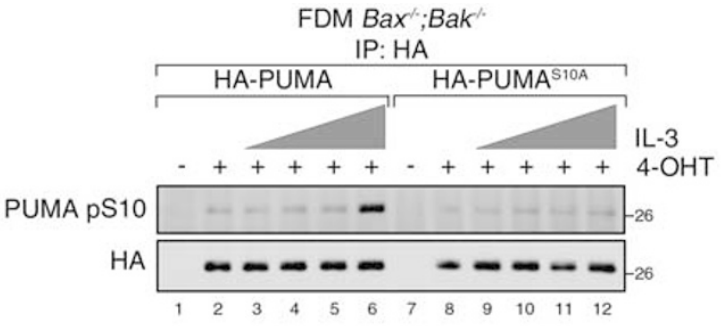

b

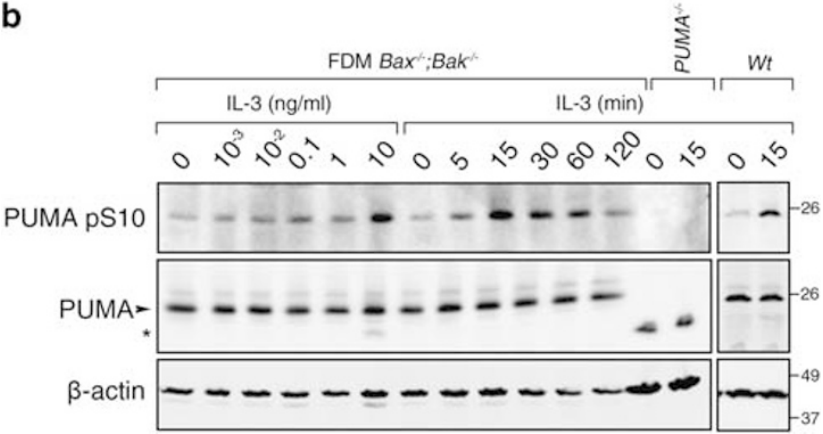

Figure 3 PUMA is phosphorylated at serine 10 by IL-3 signaling. (a) Expression of HA-PUMA wild type or HA-PUMA ${ }^{\text {S10A }}$ was induced in $\mathrm{Bax}^{-/-} ; \mathrm{Bak}^{-/-}$FDM cells with $100 \mathrm{nM} \mathrm{4-OHT}$ for $16 \mathrm{~h}$ before removal of IL-3 for $24 \mathrm{~h}$. Cells were then stimulated with IL-3 at increasing concentrations for 15 min (lanes 3 and 9 , $1.5 \times 10^{-4} \mathrm{ng} / \mathrm{ml}$; lanes 4 and $10,1.5 \times 10^{-3} \mathrm{ng} / \mathrm{ml}$; lanes 5 and $11,1.5 \times 10^{-2} \mathrm{ng} / \mathrm{ml}$ lanes 6 and 12, $7.5 \mathrm{ng} / \mathrm{ml})$. Immunoprecipitated HA-PUMA was resolved by SDSPAGE and immunoblotted using PUMA pS10 or antiHA antibodies. (b) $\mathrm{Bax}^{-1-}$ $\mathrm{Bak}^{-1-}$ FDM, PUMA ${ }^{-1-}$ FDM or FDM wild-type cells were starved of IL-3 for $24 \mathrm{~h}$. Cells were then stimulated with IL-3 for $15 \mathrm{~min}$ at the indicated concentrations or were stimulated with $10 \mathrm{ng} / \mathrm{ml} \mathrm{IL-3}$ for the indicated periods of time. Protein lysates were resolved by SDS-PAGE and immunoblotted using antibodies against PUMA pS10, total PUMA or $\beta$-actin. * indicates non-specific band

immunoprecipitated together with PUMA or a phosphorylated protein that interacts with PUMA in a serine 10-independent manner. Together, these data show that overexpressed PUMA is metabolically labeled by ${ }^{32} \mathrm{P}$ orthophosphate at the serine 10 residue by a kinase complex activated by serum or IL-3 stimulation.

Endogenous PUMA is specifically phosphorylated by IL-3 stimulation. As overexpressed PUMA was phosphorylated at serine 10 , it was important to demonstrate this in endogenous PUMA. We generated an antibody that specifically detected PUMA phosphorylated at serine 10, referred to as antiPUMA pS10 (see Material and Methods). Antibody specificity was confirmed by probing immunoprecipitated HA-PUMA or HA-PUMA ${ }^{\text {S10A }}$ from IL-3stimulated FDM cells (Figure $3 \mathrm{a}$ ). We observed an increased signal corresponding to the phosphorylated PUMA in cells expressing wild type but not PUMA ${ }^{\mathrm{S10A}}$. To determine whether endogenous PUMA was phosphorylated following IL-3 stimulation, $\mathrm{Bax}^{-/-} ; \mathrm{Bak}^{-/-}$FDM cells starved of IL-3 overnight and were re-stimulated with IL-3 in a dose- or timedependent manner (Figure 3b). Lysates probed with antiPUMA pS10 indicated rapid phosphorylation of endogenous PUMA, detectable $5 \mathrm{~min}$ after the IL-3 stimulation and peaking at $15 \mathrm{~min}$. Dose-dependent phosphorylation occurred in response to IL-3 with maximal phosphorylation observed at $10 \mathrm{ng} / \mathrm{ml}$ (Figure $3 \mathrm{~b}$ ). FDM cells derived from wild-type or $P U M A^{-1-}$ mice cultured with or without IL-3 re-stimulation were used as controls. These controls confirmed PUMA phosphorylation in the presence of $B a x$ and Bak, and that no signal was detected in the absence of PUMA. Fractionation of cells into cytosolic and membrane fractions following IL-3 re-stimulation confirmed that PUMA and phosphorylated PUMA localized to the membrane fraction containing mitochondrial proteins (Supplementary Figure 3). Together, these data show that endogenous PUMA phosphorylation is induced by IL-3 signaling, and the antiPUMA pS10 antibody detects endogenous PUMA phosphorylated at serine 10 .

PUMA $^{\text {S10A }}$ is a more stable protein. We considered whether serum- or IL-3-activated PUMA phosphorylation regulated PUMA stability. We probed western blots of lysates from $\mathrm{Bax}^{-/-} ; \mathrm{Bak}^{-/-} \mathrm{FDM}$ cells or $\mathrm{Bax}^{-/} ; \mathrm{Bak}^{-/-}$murine embryonic fibroblast (MEFs), which had been pulsed with 4-OHT for $4 \mathrm{~h}$ to induce expression of the wild-type PUMA, or PUMA in which serine 10 was changed to alanine $\left(P \cup M A^{S 10 A}\right)$, aspartate $\left(P U M A^{S 10 D}\right)$ or glutamate $\left(P U M A^{S 10 E}\right)$. These cells were subjected to IL-3 or serum deprivation followed by re-stimulation, in the presence of cycloheximide (CHX) (Figure 4a and Supplementary Figure 4). In FDM cells, wild-type PUMA levels steadily declined over $60 \mathrm{~min}$ before reaching baseline levels. In contrast, levels of PUMA serine 10 mutant proteins remained elevated over the $2-h$ time course of the experiment. PUMA ${ }^{\text {S10D }}$ and PUMA ${ }^{\text {S10E }}$ levels remained elevated suggesting that these mutations abolish serine 10 function. In MEFs, following serum and $\mathrm{CHX}$ stimulation, wild-type PUMA levels fell quickly to baseline over $30 \mathrm{~min}$. As in FDM cells, PUMA serine 10 mutants had significantly longer half-lives than wild-type PUMA; however, in contrast to FDM cells, levels ultimately declined over the course of the experiment. These results show that the mutation of PUMA serine 10 prolonged PUMA half-life, and suggest that serine 10 phosphorylation targets PUMA for degradation. As aspartate and glutamate mutations of serine 10 have a similar effect to alanine mutation, it suggests serine 10-dependent regulation of PUMA stability cannot be mimicked by an acidic, negatively charged residue in that position, but specifically requires a serine 10 residue.

We also measured how the mutation of PUMA serine 10 influenced the ability of PUMA to induce apoptosis by determining the viability of wild-type FDM cells, in which PUMA or mutant PUMA expression was induced by $4-\mathrm{OHT}$. All PUMA constructs induced apoptosis (Supplementary Figure 5a) although PUMA ${ }^{\mathrm{S10A}}$ induced apoptosis more rapidly than the wild type. PUMA ${ }^{S 10 D}$ induced apoptosis at a similar rate to PUMA ${ }^{S 10 A}$, and PUMA ${ }^{S 10 E}$ functioned similarly to wild-type PUMA. As all the PUMA mutants were able to induce apoptosis, we used co-immunoprecipitation to confirm PUMA and PUMA mutants retained binding to $\mathrm{Bcl}-\mathrm{x}_{\mathrm{L}}$ and Mcl-1 (Supplementary Figure 5b), and induce Bax conformational change detected with a conformation-specific antiBax antibody (Supplementary Figure 5c). These data are consistent with previously published mutational analyses of PUMA serine $10 .^{12}$ 


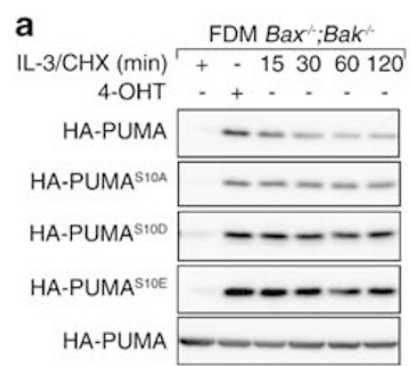
MEF Bax;Bak
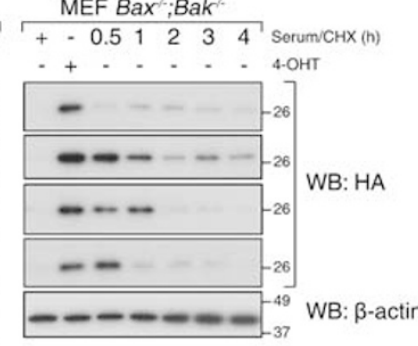

b
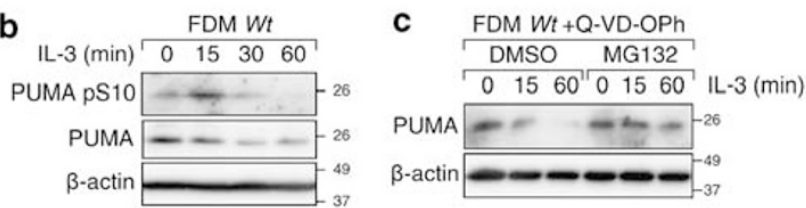

d

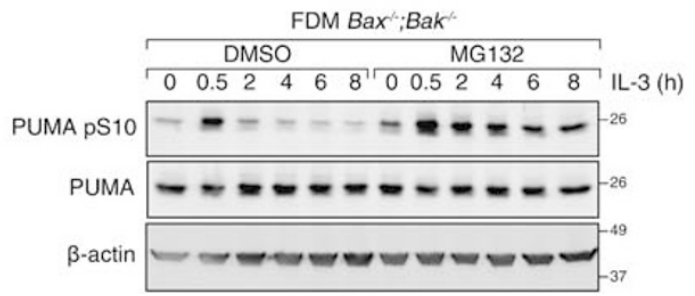

Figure 4 PUMA serine 10 phosphorylation regulates PUMA degradation through the proteasome. (a) Expression of wild-type HA-PUMA, HA-PUMA ${ }^{\mathrm{S10A}}$,

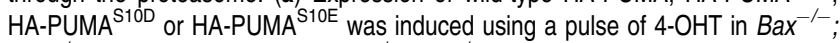
$\mathrm{Bak}^{-1-}$ FDM cells (for $4 \mathrm{~h}$ ) or $\mathrm{Bax}^{-/-} ; \mathrm{Bak}^{-1-}$ MEFs (for $2 \mathrm{~h}$ ) during a period of serum or IL-3 deprivation for $4 \mathrm{~h}$. Cells were re-stimulated with IL-3 $(10 \mathrm{ng} / \mathrm{ml})$ or serum and $\mathrm{CHX} ; 20 \mu \mathrm{g} / \mathrm{ml}$ for the indicated periods of time. Cell lysates were resolved by SDS-PAGE and probed with an antiHA antibody to detect induced HA-PUMA expression ( $\beta$-actin loading control for HA-PUMA samples are shown, loading controls for each blot are shown in Supplementary Figure 5). (b) Wild-type FDM cells were starved of IL-3 for $16 \mathrm{~h}$. Cells were then stimulated with IL-3 $(10 \mathrm{ng} / \mathrm{ml})$ for the indicated periods of time. Protein lysates were resolved by SDS-PAGE before being immunoblotted using antibodies against PUMA pS10, total PUMA or $\beta$-actin. (c) Wild-type FDM cells were starved of IL-3 for $16 \mathrm{~h}$ in the presence of $10 \mu \mathrm{M}$ Q-VD-OPh. Cells were then pre-treated with either $0.1 \%(\mathrm{v} / \mathrm{v})$ DMSO or $25 \mu \mathrm{M}$ MG132 for $30 \mathrm{~min}$ before the re-addition of IL-3 $(10 \mathrm{ng} / \mathrm{ml})$ for the indicated periods of time. Protein lysates were resolved by SDS-PAGE before being immunoblotted using antibodies against total PUMA or $\beta$-actin. (d) $B a x^{-1-} ; B^{-k^{-/-}}$ FDM cells were starved of IL-3 for $16 \mathrm{~h}$. Cells were then pre-treated with either $0.1 \%$

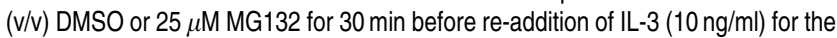
indicated periods of time. Cells were then lysed, proteins were resolved by SDSPAGE and then immunoblotted using antibodies against PUMA pS10, total PUMA or $\beta$-actin

We probed lysates from IL-3-stimulated FDM cells with the antiPUMA pS10 and a total PUMA antibody to determine the effect of IL-3 stimulation on endogenous PUMA stability. PUMA serine 10 phosphorylation peaked after $15 \mathrm{~min}$ before returning to the baseline levels by $30 \mathrm{~min}$ (Figure $4 \mathrm{~b}$ ). The disappearance of PUMA phosphorylated at serine 10 after 30 min coincided with a decline in the total PUMA protein levels. This observation confirms the data from overexpressed PUMA, that IL-3-regulated phosphorylation of endogenous PUMA at serine 10 regulates total PUMA levels in wild-type cells.

To determine the pathway responsible for the regulation of PUMA stability, we starved wild-type FDM cells of IL-3 in the presence of the pan-caspase inhibitor, Q-VD-Oph, before stimulating the cells with IL-3 in the presence or absence of the proteasomal inhibitor MG132. After $60 \mathrm{~min}$ of IL-3 stimulation, the PUMA protein levels had fallen significantly (Figure 4c). However, in cells treated with MG132 before IL-3 stimulation, PUMA protein levels remained elevated. We also observed MG132-inhibitable degradation of phosphorylated PUMA in the $\mathrm{Bax}^{-/-} ; \mathrm{Bak}^{-/-}$FDM cells stimulated with IL-3. MG132 substantially prolonged the half-life of phosphorylated PUMA without significantly affecting the total PUMA levels (Figure 4d). The probable explanation for the apparently stable total PUMA levels in the $\mathrm{Bax}^{-/-} ; \mathrm{Bak}^{-/-}$FDM cells is that changes in PUMA expression were not detectable above the substantially higher levels of endogenous PUMA expression. Nevertheless, the pathway which induces serine 10 phosphorylation remains intact in the $\mathrm{Bax}^{-1-} ; \mathrm{Bak}^{-/-} \mathrm{FDM}$ cells. The increase in endogenous phosphorylated PUMA, together with a decline in total endogenous PUMA levels in wild-type cells (Figures $4 \mathrm{~b}$ and $\mathrm{c}$ ), most accurately reflects normal physiology. These result shows that phosphorylated PUMA undergoes proteasomal degradation in a manner that is blocked by MG132.

PUMA phosphorylation is dependent on an intact IKK complex. To identify the kinase responsible for the phosphorylation of PUMA, we treated IL-3-stimulated $\mathrm{Bax}^{-1-}$; $\mathrm{Bak}^{-1-}$ FDM cells with a variety of kinase inhibitors (Figure 5a). Staurosporine was used as a positive control. The IKK inhibitor, IKK inhibitor VII, an ATP-competitive inhibitor of $\mathrm{I} \kappa \mathrm{B}$ kinase $(\mathrm{IKK})^{14}$ was the only inhibitor that consistently blocked PUMA phosphorylation in response to IL-3 stimulation.

This data suggested that IL-3 receptor signaling induced IKK activity. IKK activation is typically associated with $\mathrm{NF}_{\kappa} \mathrm{B}$ activation after signaling through TNF and toll receptors. To confirm that IL-3 activated IKK, western blots of lysates from $\mathrm{Bax}^{-1-} ; \mathrm{Bak}^{-1-}$ FDM cells that were stimulated with IL-3 in a dose- or time-dependent manner were probed with antibodies against the unphosphorylated and phosphorylated forms of IKK. Phosphorylated IKK was detected in cells treated with $1 \mathrm{ng} / \mathrm{ml} \mathrm{IL-3}$, and phosphorylation increased with higher doses of IL-3 (Figure $5 \mathrm{~b}$ ). Further, phosphorylation of IKK was blocked with a JAK inhibitor, consistent with JAK2 being the tyrosine kinase required for $\mathrm{IL}-3$ receptor signaling ${ }^{15}$ and suggesting IKK activation by IL-3 signaling first requires JAK activation. In the time course experiments, IKK phosphorylation was observed within $5 \mathrm{~min}$ of stimulation (Figure $5 \mathrm{~b}$ ). When these lysates were probed with antiPUMA pS10, we observed a concomitant increase in phosphorylated PUMA. Total PUMA levels remained consistent, as we have observed previously in $\mathrm{Bax}^{-1-} ; \mathrm{Bak}^{-/-}$FDM cells. These data reveal a correlation between the IKK activation in response to IL-3 stimulation and PUMA phosphorylation.

To confirm that IKK is required for PUMA phosphorylation, we expressed PUMA in MEFs derived from wild-type mice or mice lacking either of the kinase components of the IKK complex, IKK1 or IKK2. Phosphorylated PUMA was not detected in the MEFs lacking either IKK1 or IKK2, despite similar induced PUMA expression levels (Figure 6a). Immunoprecipitated PUMA ${ }^{\mathrm{S1OA}}$ served as a negative control 
a

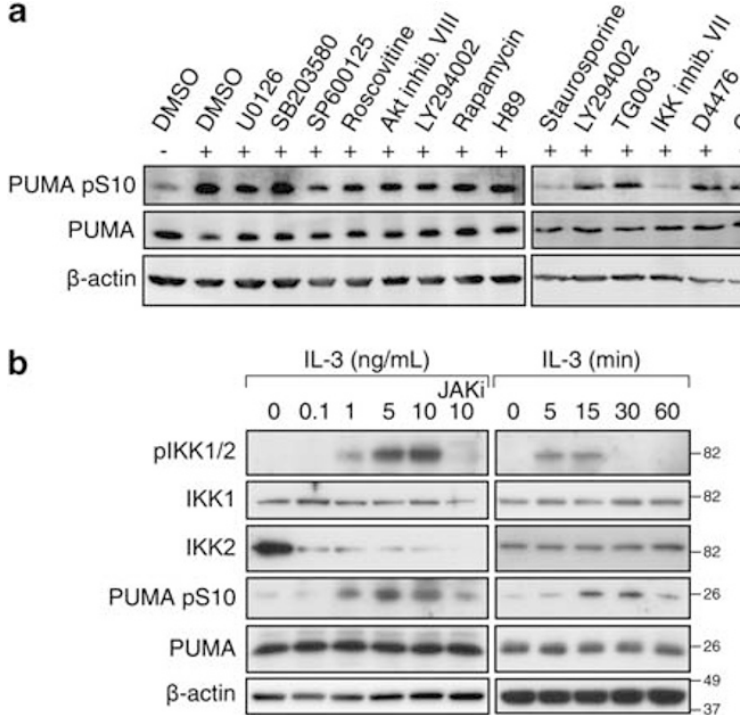

Figure 5 IL-3 signaling activates the IKK signaling complex. (a) FDM wild-type cells were starved of IL-3 for $16 \mathrm{~h}$. Cells were then pre-treated for $30 \mathrm{~min}$ with either $0.2 \%(\mathrm{v} / \mathrm{v}) \mathrm{DMSO}$ or the kinase inhibitors U0126 $(10 \mu \mathrm{M}), \mathrm{SB} 203580(10 \mu \mathrm{M})$, SP600125 $(10 \mu \mathrm{M})$, roscovitine $(100 \mu \mathrm{M})$, Akt inhibitor VIII $(10 \mu \mathrm{M})$, rapamycin $(10 \mu \mathrm{M})$, LY294002 $(20 \mu \mathrm{M}), \mathrm{H} 89(10 \mu \mathrm{M})$, TG003 $(10 \mu \mathrm{M})$, IKK inhibitor VII $(5 \mu \mathrm{M})$, D4476 $(10 \mu \mathrm{M})$, CK2 inhibitor II $(10 \mu \mathrm{M})$ and staurosporine $(1 \mu \mathrm{M})$. Cells were then stimulated with IL-3 $(10 \mathrm{ng} / \mathrm{ml})$ for $15 \mathrm{~min}$. Protein lysates were resolved by SDSPAGE and then immunoblotted using antibodies against PUMA pS10, total PUMA or $\beta$-actin. (b) $\mathrm{Bax}^{-1-}$;Bak ${ }^{-/-}$FDM cells were starved of IL-3 for $16 \mathrm{~h}$. Cells were then stimulated with IL-3 for 5 min at the indicated concentrations in the presence or absence of JAK inhibitor I (JAKi, $1 \mu \mathrm{M})$ or were stimulated with IL-3 $(10 \mathrm{ng} / \mathrm{ml})$ for the indicated periods of time. Protein lysates were resolved by SDS-PAGE before being immunoblotted using antibodies against phospho-IKK1/2, total IKK1, total IKK2, PUMA pS10, PUMA and $\beta$-actin

for antiPUMA pS10. When this experiment was repeated in $\mathrm{Nemo}^{-/-}$MEFs, PUMA phosphorylation was also unable to be detected (data not shown). This data shows that both IKK1 and IKK2 as part of an IKK1/IKK2/Nemo complex are responsible for the PUMA phosphorylation.

Our data provided strong evidence that IKK activity was required for PUMA phosphorylation but did not prove that either IKK1 or IKK2 could directly phosphorylate PUMA. To test this possibility, a radiometric in-vitro kinase assay was performed using wild-type HA-PUMA or HA-PUMA ${ }^{\text {S10A }}$ and recombinant IKK1 or IKK2. Incubation of IKK1 and IKK2 with recombinant $\mathrm{I} \kappa \mathrm{B} \alpha$, a known IKK2 substrate, was used as a positive control and the levels of $\mathrm{I}_{\kappa} \mathrm{B} \alpha$ phosphorylation by IKK1 indicate background phosphorylation in the assay. Analysis of ${ }^{32} \mathrm{P}$ labeling demonstrated that wild-type PUMA was phosphorylated by IKK1 but not by IKK2 (Figure 6b). Recombinant IKK2 was functional and able to phosphorylate $\mathrm{I}_{\kappa} \mathrm{B} \alpha$. The incorporation of ${ }^{32} \mathrm{P}$ into PUMA ${ }^{\mathrm{S} 10 \mathrm{~A}}$ by IKK1, and into wild-type PUMA or PUMA ${ }^{\mathrm{S1OA}}$ in the presence of IKK2, was similar to the background phosphorylation. This in-vitro kinase assay demonstrates that IKK1 but not IKK2 can directly phosphorylate PUMA at serine 10.

Although it is unusual to demonstrate by co-immunoprecipitation a direct association between kinase and substrate, we immunoprecipitated overexpressed PUMA and probed the immunoprecipitates with antibodies against IKK1 and IKK2
(Figure 6c). We used either a full-length wild-type PUMA construct or a loss-of-function PUMA ${ }^{4 E}$ mutant in which four of the key residues of the $\mathrm{BH} 3$ domain are mutated to glutamate, ${ }^{8,13}$ so that PUMA could be expressed without inducing apoptosis. IKK1, but not IKK2 co-immunoprecipitated with wild-type PUMA or PUMA ${ }^{4 E}$. The specificity of this interaction was confirmed by expressing $P U M A^{4 E}$ in wild-type or $I K K 1^{-1-}$ MEFs (Supplementary Figure 6). This data demonstrates that endogenous IKK1 directly binds overexpressed PUMA, and together with the in-vitro kinase data and data from IKK-deleted cells strongly suggest that a heteromeric IKK complex of IKK1, IKK2 and IKK $\gamma / \mathrm{Nemo}$ is responsible for the PUMA phosphorylation and that IKK1 is the kinase directly responsible for PUMA phosphorylation.

To determine the significance of IKK phosphorylation of PUMA in regulating cell survival, MEF and FDM cells bearing genetic deletion of PUMA were incubated with IKK inhibitor VII. Wild-type MEF cells were sensitive to IKK inhibition with a majority of cells losing membrane integrity and staining positive for propidium iodide $(\mathrm{PI})$ uptake after $24 \mathrm{~h}$ of inhibitor treatment (Figure 6d). In contrast, the $P U M A^{-1-}$ MEFs were significantly protected with around 2.5 -fold less cells becoming $\mathrm{PI}$ positive. Wild-type FDM cells were also sensitive to treatment with the IKK inhibitor VII, and again deletion of PUMA significantly protected the cells albeit to a lesser extent than that seen in MEFs (Figure 6d). These data demonstrate that PUMA has a significant role in apoptosis induced by the inhibition of IKK.

We have previously shown that FDM cells lacking PUMA are more able to form colonies when IL-3 is restored after a period of IL-3 deprivation. ${ }^{11}$ Therefore, we reasoned that the disruption of an intact IKK complex would diminish colony formation, because such cells would be less able to clear accumulated PUMA protein. To test this prediction, we generated FDM cells from IKK2-deficient mice and compared these with wild-type FDMs for the ability to form colonies in soft agar culture after varying times of IL-3 deprivation (Figure 6e). IKK2-deleted FDM cells generated 5-10-fold fewer colonies than the wild-type cells as the period of IL-3 deprivation continued. This data confirms that IKK contributes to the ability of surviving cells to proliferate when IL-3 signaling is restored after a period of deprivation. Together with the IKK inhibitor data (Figure 6d), these data link IKK-dependent regulation of PUMA to survival signaling transduced by IL-3.

\section{Discussion}

PUMA is transcriptionally regulated by p53 following DNA damage ${ }^{16,17}$ or IL-3 deprivation. ${ }^{18}$ PUMA transcription is also regulated by FoxO3a ${ }^{19}$ and repressed by Slug. ${ }^{20}$ We have identified a novel mechanism of PUMA post-translational modification in response to serum or cytokine signaling. PUMA is phosphorylated on the conserved serine 10 residue. Phosphorylation of serine 10 directly contributes to cell survival by targeting PUMA for proteasomal degradation.

Phosphorylation and proteasomal degradation of PUMA provides a pathway for clearing PUMA expressed in response to an apoptotic stimulus but in the cells that do not commit to apoptosis. We mimicked such physiological perturbations by first starving cells of, and then restoring, serum or IL-3. Cells 


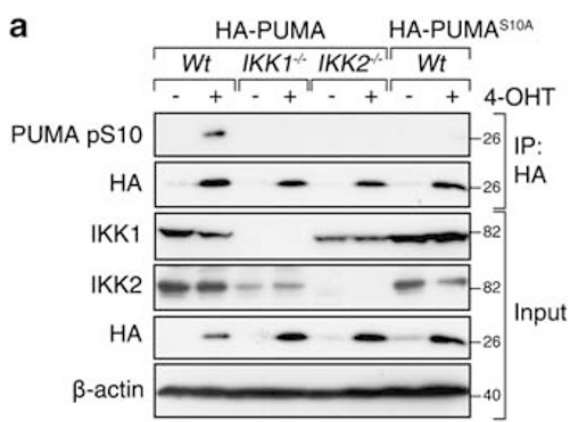

b

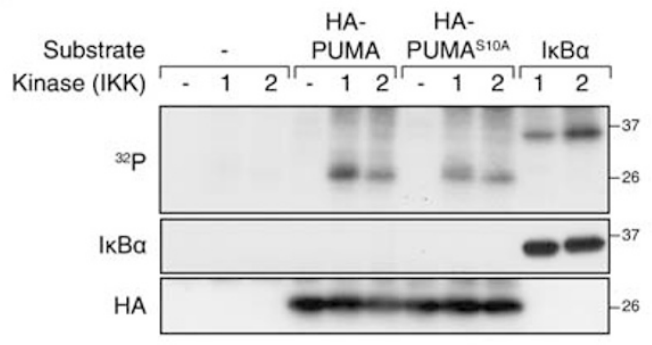

c
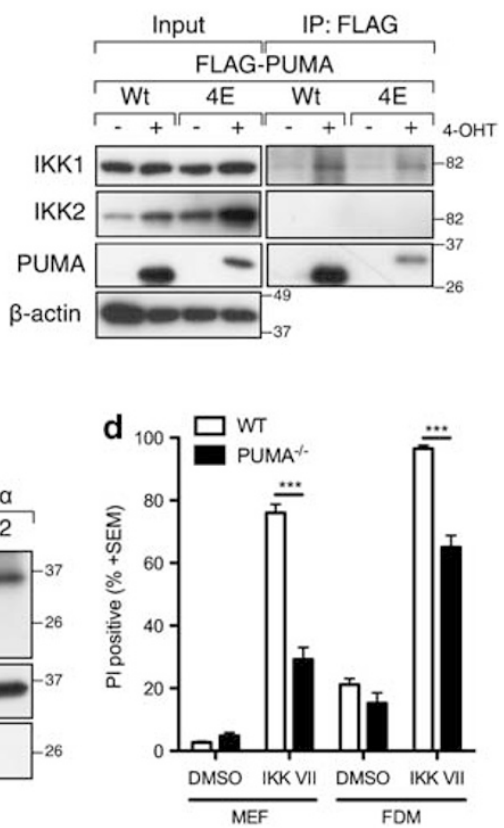

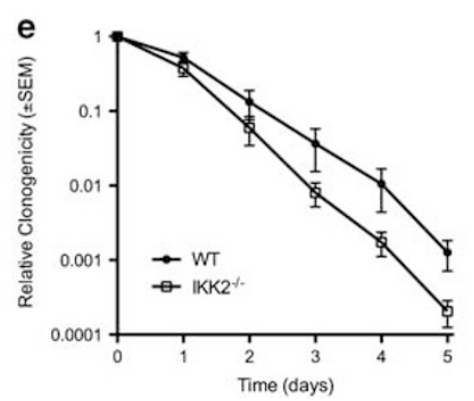

Figure 6 IKK phosphorylates PUMA to regulate cell survival. (a) HA-PUMA was expressed in wild-type, IKK $1^{-/-}$or IKK2-/- MEFs under the control of a 4-OHT-inducible promoter. PUMA was immunoprecipitated from protein lysates made in the presence or absence of 4-OHT and proteins were resolved using SDS-PAGE. Blots were probed with antibodies against HA, PUMA pS10, IKK1, IKK2 and $\beta$-actin. (b) HA-PUMA wild type or HA-PUMA ${ }^{\text {S10A }}$ were expressed in HEK 293T cells. HA-tagged proteins were immunoprecipitated and phosphorylated in vitro by performing a radiometric kinase assay using a recombinant IKK1 or IKK2 (see Material and Methods). Recombinant I $\kappa \mathrm{B} \alpha$ was used as a positive control substrate for IKK2 phosphorylation. The kinase reaction was resolved using SDS-PAGE with blots probed with antibodies against $I \mathrm{~B} \alpha$ and $\mathrm{HA}$. Incorporation of radioactive phosphates into the proteins was visualized by autoradiography. (c) A Flag-tagged PUMA or PUMA ${ }^{4 \mathrm{E}}$ was expressed in $\mathrm{Bax}^{-/-} ; \mathrm{Bak}^{-1-} \mathrm{MEFs}^{-\mathrm{M}}$ under the control of a 4-OHT-inducible promoter. PUMA was immunoprecipitated from lysates made in the presence or absence of 4-OHT and proteins were resolved using SDS-PAGE. Blots were probed with antibodies against PUMA, IKK1, IKK2 and $\beta$-actin. PUMA ${ }^{4 E}$ runs at a higher apparent molecular weight than the wild-type PUMA. (d) Wild-type and PUMA ${ }^{-1}$ MEFs and FDM cells were treated with $5 \mu \mathrm{M}$ IKK inhibitor VII or DMSO control for $24 \mathrm{~h}$. Cell viability was determined by analyzing PI uptake by flow cytometry. $P$-values were calculated using unpaired $t$-test. Results were generated from three independent experiments. MEF cells WT $n=4, P U M A^{-\prime-} n=4$ ${ }^{* \star *} P=<0.0001$, FDM cells WT $n=8, P U M A^{-1-} n=8^{* * *} P=<0.0001$. (e) Multiple independent clones of IL-3-dependent wild-type or IKK2 ${ }^{-1-}$ FDM cells were starved of IL-3 over a 5-day time course. Cells were plated in soft agar with IL-3 after the indicated period of time without IL-3. Colonies were counted after 3 weeks and relative clonogenicity was determined by comparing with day 0 . Results were generated from three independent experiments. WT $n=5, I K K 2^{-/-} n=6$

which express PUMA in response to sublethal death stimuli require a rapid and specific mechanism to degrade PUMA and prevent accumulation of PUMA to lethal levels. This is demonstrably different to previously described mechanism of PUMA regulation by cytokines or serum, ${ }^{21}$ in which cytokine-receptor signaling was sufficient to repress transcriptional upregulation of PUMA. In the model we describe, restoration of a survival signal before apoptosis is irrevocable and induces the rapid activation of IKK1 and PUMA phosphorylation on serine 10 to rapidly reduce PUMA to the baseline levels.

Mutation of serine 10 to alanine, aspartic acid or glutamic acid all resulted in a prolonged PUMA half-life following either
IL-3 or serum stimulation. The substitution of a negatively charged, acidic residue in place of serine 10 did not increase PUMA degradation indicating these mutations in PUMA do not function as phosphomimics, but do clearly show the specific requirement for a serine residue at this position to promote PUMA degradation. This may be because the phosphorylated serine co-ordinates a protein-protein interaction, which ultimately results in PUMA degradation, but the nature of any such interaction is unknown.

Our results are functionally and mechanistically different to previous observations of phosphorylation of other $\mathrm{BH} 3$-only proteins. Serine and threonine phosphorylation of Bad has been well described and inhibits the pro-apoptotic function of 
Bad either by sequestering Bad to the chaperone protein $14-3-3^{22,23}$ or inhibiting the interaction between Bad and $\mathrm{BCl}-\mathrm{x}_{\mathrm{L}}{ }^{24}$ Mutation of PUMA serine 10 has no effect on binding to the antiapoptotic Bcl-2 family members. PUMA degradation after phosphorylation is more reminiscent of the phosphorylation of Bim on three serine residues encoded in exon 3, in a manner dependent on MAPK signaling, in response to serum stimulation. $^{25}$ Thus, there are probably several kinasedependent mechanisms that result in the degradation of $\mathrm{BH} 3-o n l y$ proteins in cells that regain survival signals after a potential apoptotic insult, such as growth factor or serum deprivation. Recently, PUMA phosphorylation at serine 10 was independently described. ${ }^{12}$ This work also demonstrated that phosphorylation of overexpressed PUMA at serine 10 resulted in an increased PUMA turnover. We have been working on to identify the stimuli and the kinase pathway responsible.

We have provided several compelling lines of evidence that IKK1 is the kinase responsible for PUMA phosphorylation at serine 10 . IKK is a complex of two related kinases, IKK1/IKK $\alpha$ and IKK2/IKKß, and a regulatory subunit IKK $\gamma / \mathrm{Nemo}{ }^{26}$ The IKK complex typically phosphorylates $\mathrm{I}_{\kappa} \mathrm{B}$, which targets this protein for proteasomal degradation, and as a consequence $\mathrm{NF}_{\kappa} \mathrm{B}$ is activated. Thus the requirement for IKK in PUMA phosphorylation was surprising, and it remains to be determined how the molecular mechanisms of IKK activation in response to IL-3 or serum stimulation compares with TNFR1 activation of IKK. Our data show that IL-3-dependent IKK activation is blocked by a JAK inhibitor, consistent with a requirement for JAK2 tyrosine kinase activity, which is the tyrosine kinase associated with the IL-3 receptor. ${ }^{15}$ Some precedence exists connecting IKK to the closely related GM-CSF receptor, and connecting IKK to PUMA regulation. An active mutant of the $\beta$-common chain ${ }^{27,28}$ shared by the IL-3, GM-CSF and IL-5 receptors results in constitutive $\mathrm{I}_{\kappa} \mathrm{B}$ phosphorylation, and IKK2 can co-immunoprecipitate with GM-CSF receptor $\alpha$-chain. ${ }^{29}$ Further, the enforced expression of a dominant negative $\mathrm{IKK} \gamma / \mathrm{Nemo}$ in keratinocytes increased the levels of PUMA protein, even in the absence of an apoptotic stimulus. ${ }^{30}$ The stage is now set to map the molecular mechanisms that link IL-3 receptor engagement to IKK activation in myeloid cells.

In conclusion, we have described a new mechanism for the post-translational regulation of PUMA. Phosphorylated PUMA is degraded in cells in which PUMA expression is induced, but which do not reach the threshold of irrevocable commitment to apoptosis. PUMA phosphorylation is dependent on an intact IKK complex, and our evidence strongly indicates that IKK1 is part of a heteromeric IKK1/IKK2 complex that is directly responsible for PUMA phosphorylation. Elucidating the molecular details by which cytokines such as IL-3 activate IKK may offer novel ways in which apoptosis pathways might be regulated for therapeutic gain.

\section{Materials and Methods}

Antibodies and chemicals. Polyclonal rabbit antibodies against PUMA phosphorylated at $S 10$ (pS10) were raised by immunizing rabbits with the peptide ARARQEGS(pS)PEPVEGLC (residues 2-18 of human PUMA- $\alpha$ ) coupled to Keyhole Limpet Hemocyanin synthesized by Mimotopes (Clayton, VIC, Australia). Antibodies were affinity purified using a PUMA pS10 peptide column (same peptide as immunogen). The antibody was used for immunoblotting and was selected for giving a strong signal in western blotting. The antibody against PUMA was from ProScience (Sapphire Bioscience, Redfern, NSW, Australia). The antibody against $\beta$-actin was from Calbiochem (Merck, Darmstadt, Germany). Antibodies against $\mathrm{Bcl}-\mathrm{x}_{\mathrm{L}}, \mathrm{VDAC}, \mathrm{I} \kappa \mathrm{B} \alpha$, IKK1, IKK2 (L570), phospho-IKK1/2 were from Cell Signaling (Genesearch, Arundel, QLD, Australia). The antibody against Mcl-1 was from Rockland (Gilbertsville, PA, USA). The antibody against EF-1 $\alpha$ (clone CBP-KK1) was from Upstate (Billerica, MA, USA). The antibody against hemagglutinin (HA) (clone 12CA5) was from MAbSA (Gillies Plains, SA, Australia). Recombinant mouse IL-3 was purchased from Shenendoah Biotechnology (Jomar Bioscience, Kensington, SA, Australia). 4-OHT, MG132 and $\mathrm{CHX}$ were purchased from Sigma (Castle Hill, NSW, Australia). Q-VD-OPh was purchased from R\&D systems (Bio-scientific, Gymea, NSW, Australia). Small molecule kinase inhibitors were purchased from a variety of manufacturers. U0126 was purchased from Cell Signaling. Roscovitine was purchased from BIOMOL (Sapphire Bioscience, Redfern, NSW, Australia). SB203580, H89, Staurosporine, TG003, D4476 and CK2 inhibitor II were purchased from Sigma. SP600125, Akt inhibitor VIII, LY294002, rapamycin, JAK inhibitor I and IKK inhibitor VII were purchased from Calbiochem.

Plasmids, cDNAs and mutagenesis. HA-tagged human PUMA- $\alpha$ cDNA in a pEF-HA-hygro vector was provided by Professor Sharad Kumar (Centre for Cancer Biology, Adelaide, SA, Australia). Serine residues were substituted with alanine in the human PUMA- $\alpha$ CDNA using oligonucleotide-directed mutagenesis. Mutagenesis primers $\left(5^{\prime}-3^{\prime}\right)$ : S9A, forward: $5^{\prime}$-GCA CGC CAG GAG GGC GCC TCC CCG GAG CCC GTA GAG-3', reverse: $3^{\prime}$-CTC TAC GGG CTC CGG GGA GGC GCC CTC CTG GCG TGC-5'; S10A, forward: 5'-GCA CGC CAG GAG GGC AGC GCC CCG GAG CCC GTA GAG-3', reverse: 3'-CTC TAC GGG CTC CGG GGC GCT GCC CTC CTG GCG TGC- $5^{\prime}$. The mutations were confirmed by nucleotide sequencing and the mutant PUMA CDNAs were subcloned using a BamHI/Xbal fragment into the eukaryotic expression vector pEF-HA-hygro and pF-5XUAS-HA-SV40-puro. All constructs were sequenced for authenticity and purified using QIAGEN maxiprep kits before use (QIAGEN, Clifton Hill, VIC, Australia).

Cell culture. The HEK 293T cell line was maintained in DMEM supplemented with $10 \%$ (v/v) heat-inactivated fetal bovine serum (Gibco, Melbourne, VIC, Australia). FDM cell lines from a variety of genetic backgrounds were maintained in DMEM supplemented with $10 \%(\mathrm{v} / \mathrm{v}) \mathrm{HI}$ FBS and $0.25 \mathrm{ng} / \mathrm{ml} \mathrm{mlL}-3$. MEF cells from a variety of genetic backgrounds were maintained in DMEM supplemented with $10 \%$ (v/v) FBS. $\mathrm{Bax}^{-1} ; \mathrm{Bak}^{-/-}$and $\mathrm{PUMA}^{-/-} \mathrm{FDM}$ and MEF cells have been described previously. ${ }^{13} I K K 1^{-/-}$and IKK2 $2^{-/-}$MEF cells and $I K K 2^{-/-}$mouse fetal liver cells were a kind gift from Dr. Vinay Tergaonkar (A*STAR, Proteos, Singapore). IKK2 ${ }^{-1}$ FDM cells were generated from IKK2 ${ }^{-1}$ mouse fetal liver cells as previously described. $^{31}$

For DNA transfection, HEK 293T cells were grown on a 10-cm plate until they were around $70 \%$ confluent. Cells were transfected with PUMA cDNA in a pEF-HAhygro vector using $24 \mu \mathrm{g}$ of DNA and $60 \mu \mathrm{l}$ of Lipofectamine 2000 following the manufacturer's instructions (Invitrogen, Melbourne, VIC, Australia). Cells were cultured at $37^{\circ} \mathrm{C}$ before medium was replaced $6 \mathrm{~h}$ after the addition of transfection reagents.

The lentiviral-inducible expression system used has two components. The first is a fusion protein of Gal4 with a modified estrogen receptor. The fusion protein is constitutively expressed from an ubiquitin promoter (GEV16). In the absence of 4-OHT, this fusion protein is held in an inactive state in the cytosol bound to heatshock protein-90 (HSP90). The second component is the gene-of-interest downstream of a promoter consisting of five UAS sites (pF 5xUAS SV40 puromycin). In the presence of 4-OHT, the Gal4-ER fusion protein dissociates from HSP90 and translocates to the nucleus to drive expression. Lentivirus particles were generated by transfecting HEK 293T cells with $p C M V-\Delta R 8$ and pVSV-G lentiviralpackaging constructs in addition to the $\mathrm{pF} 5 \mathrm{xUAS}$ SV40 puromycin containing the gene-of-interest using Lipofectamine 2000 . After $48 \mathrm{~h}$ supernatants were collected, filtered and either stored at $-80^{\circ} \mathrm{C}$ or mixed $1: 1$ in the presence of $4 \mu \mathrm{g} / \mathrm{ml}$ polybrene and added to cells. Stably infected cells were selected using puromycin and hygromycin.

Cell lysis. Total cell lysates were prepared by lysing either directly into SDS load buffer ( $250 \mathrm{mM}$ Tris- $\mathrm{HCl}, 4 \%$ glycerol, $5 \%$ SDS, $0.25 \%$. bromophenol blue), NP40 lysis buffer (10 mM Tris-HCl pH 7.4, $137 \mathrm{mM} \mathrm{NaCl}, 10 \%$ glycerol, 1\% Nonidet P-40), 
CHAPS lysis buffer (20 mM Tris-HCl pH 7.4, $135 \mathrm{mM} \mathrm{NaCl}, 1.5 \mathrm{mM} \mathrm{MgCl}_{2}, 1 \mathrm{mM}$ EGTA, $10 \%$ glycerol, $1 \%$ CHAPS), RIPA buffer ( $150 \mathrm{mM} \mathrm{NaCl}, 50 \mathrm{mM}$ Tris- $\mathrm{HCl}$, $0.5 \%$ Sodium deoxycholate, $0.1 \%$ SDS, $1 \%$ NP40) supplemented with complete protease inhibitor cocktail tablets (Roche, Mannheim, Germany) and phosphatase inhibitors ( $2 \mathrm{mM}$ sodium fluoride, $10 \mathrm{mM} \beta$-glycerophosphate, $2 \mathrm{mM} \mathrm{Na}_{3} \mathrm{VO}_{4}$ ) at a density of $5 \times 10^{7}-1 \times 10^{8} \mathrm{cells} / \mathrm{ml}$. Cells were fractionated into cytosolic and membrane fractions at a density of $1 \times 10^{8} \mathrm{cell} / \mathrm{s} / \mathrm{ml}$. Cytosolic fractions were generated by incubating the cells in digitonin (stock solution $20 \mathrm{mg} / \mathrm{ml}$ ) diluted 1: 125 in HMKEE (20 mM HEPES pH 7.4, 5 mM MgCl 2,10 mM KCL, 1 mM EDTA, $1 \mathrm{mM}$ EGTA) with $250 \mathrm{mM}$ sucrose and complete protease inhibitor cocktail tablets on ice for $15 \mathrm{~min}$. Supernatant (cytosolic fraction) was collected after centrifugation at $500 \times g$ for $10 \mathrm{~min}$. The pellet was resuspended in HMKEE, $250 \mathrm{mM}$ sucrose and $0.5 \%$ Triton X-100 and incubated on ice for $30 \mathrm{~min}$. Supernatant (membrane fraction) was collected after centrifugation at $5000 \times g$ for $10 \mathrm{~min}$.

Immunoprecipitation, SDS-PAGE, immunoblot and ECL. Following a variety of different treatment conditions cells were lysed in NP40, CHAPS or RIPA lysis buffer for $30 \mathrm{~min}$ at $4{ }^{\circ} \mathrm{C}$ followed by centrifugation of the lysate for $15 \mathrm{~min}$ at $13000 \times \mathrm{g}$ $4{ }^{\circ} \mathrm{C}$. Supernatant was incubated for $16 \mathrm{~h}$ with antiHA antibody coupled to $\mathrm{CNBr}$ activated Sepharose 4B (GE, Rydalmere, NSW, Australia) or antiFLAG antibody coupled to agarose (Sigma). The beads were then washed three times in the relevant lysis buffer before boiling for $5 \mathrm{~min}$ in SDS load buffer, either in the presence or absence of $\beta$-mercaptoethanol (reducing or non-reducing) or elution using competing peptide before separating proteins by SDS-PAGE. Lysates and immunoprecipitates were analyzed by one-dimentional SDS-PAGE under reducing and non-reducing conditions. Molecular weights were estimated using the commercially available MW markers Benchmark Pre-stained Protein Markers (Invitrogen). Proteins separated by SDS-PAGE were transferred to nitrocellulose membrane by electroblotting. Nitrocellulose and PVDF membranes were blocked in a solution of TBS $/ 0.05 \%(\mathrm{v} / \mathrm{v})$ Tween 20 containing $1 \%(\mathrm{w} / \mathrm{v})$ blocking reagent (Roche), then probed overnight at $4{ }^{\circ} \mathrm{C}$ with the indicated antibodies followed by the appropriate horseradish peroxidise secondary antibody. Proteins were detected by chemiluminescence using an ECL kit (Amersham, Little Chalfont, UK) following manufacturer's instructions. Experiments utilizing these techniques were independently performed a minimum of three times.

Mass spectrometry. HA-PUMA was overexpressed in HEK 293T or FDM cells before lysis, HA immunoprecipitation, SDS-PAGE and stained with Coomassie Brilliant Blue. The bands of interest were excised from the gel, destained and digested with $100 \mathrm{ng}$ of trypsin/sample according to the 'low salt' protocol. A total of $1 \mu \mathrm{l}$ of each sample was applied to a 600-mm AnchorChip (Bruker Daltonik GmbH, Bremen, Germany), washed with $10 \mathrm{mM}$ dihydroammonium phosphate and overlaid with a-cyano-4-hydroxycinnamic acid matrix $(0.8 \mu \mathrm{l}$ of a $0.5 \mathrm{~g} / \mathrm{l}$ solution in $90 \%$ acetonitrile (ACN) $/ 0.1 \%$ TFA). A total of $10 \mu \mathrm{l}$ of an immobilized metal affinity chromatography (IMAC, Bruker Daltonik $\mathrm{GmbH}$ ) magnetic bead suspension was pre-treated with $50 \mu \mathrm{l}$ MB-IMAC Fe wash solution 1 three times. The beads were suspended in $20 \mu \mathrm{l}$ MB-IMAC Fe wash solution 1, plus $20 \mu \mathrm{l}$ MB-IMAC binding solution before adding $1 \mu \mathrm{l}$ of the peptide sample and incubating for $45 \mathrm{~min}$ at an ambient temperature with low agitation. The supernatant was removed and the beads were washed three times with $100 \mu \mathrm{lMB}$-IMAC Fe wash solution 2, and eluted using $3 \mu \mathrm{l} 50 \% \mathrm{ACN}$ with $0.1 \%$ phosphoric acid for $10 \mathrm{~min}$ to enhance sensitivity. A total of $1 \mu \mathrm{l}$ of this eluate was subsequently applied to an AnchorChip with $1 \mu \mathrm{l}$ 2,5-dihydroxy benzoic acid (DHB - $10 \mathrm{mg} / \mathrm{ml}$ ) in $50 \%$ ACN with $0.1 \%$ phosphoric acid for MALDI-TOF MS analysis. Half of each IMAC-purified sample was diluted to $5.5 \mathrm{ml}$ with $1 \% \mathrm{FA}$ in an autosampler vial and $5 \mathrm{ml}$ chromatographed using an Agilent Protein ID Chip column assembly ( $40 \mathrm{nl}$ trap column with $0.075 \times 43 \mathrm{~mm} \mathrm{C}$-18 analytical column) housed in an Agilent HPLC-Chip Cube Interface connected to an a HCT ultra 3D-Ion-Trap mass spectrometer (Bruker Daltonik $\mathrm{GmbH}$ ). The column was equilibrated with $4 \% \mathrm{ACN} / 0.1 \% \mathrm{FA}$ at $0.5 \mathrm{ml} / \mathrm{min}$, and the samples were eluted with an ACN gradient (4-31\% in $32 \mathrm{~min})$. Ionizable species $(300<\mathrm{m} / \mathrm{z}<1200)$ were trapped, and one or two of the most intense ions eluting at the time were fragmented by CID and ETD. A specific inclusion list was used to preferentially fragment ions that corresponded in $\mathrm{m} / \mathrm{z}$ to potential phosphopeptides.

Metabolic labeling of cells. To metabolically label cells using ${ }^{32} \mathrm{P}$ orthophosphate, cells were starved into a phosphate-free medium for 4-24h before the addition of $250 \mu \mathrm{Ci}^{32} \mathrm{P}$ orthophosphate (Perkin Elmer, Glen Waverly, VIC, Australia) for $4 \mathrm{~h}$ followed by a variety of experiments. Cells were then lysed using NP40 lysis buffer before immunoprecipitation, precipitates resolved by SDS-PAGE and transferred to nitrocellulose before being exposed to x-ray film. Each metabolic labeling experiment was independently performed three times.

Immunofluorescence staining and confocal microscopy. To detect activated Bax, cells were fixed in $1 \%$ paraformaldehyde for $5 \mathrm{~min}$ at room temperature. Cells were then washed in PBS $/ 2 \%$ FCS and probed with $5 \mu \mathrm{g} / \mathrm{ml}$ antiBax mAb $(6 \mathrm{~A} 7$; Becton Dickinson, San Jose, CA, USA) in PBS/ $2 \%$ FCS and $0.3 \%$ saponin overnight at $4{ }^{\circ} \mathrm{C}$. Cells were then washed and incubated with goat antimouse $\lg G$ antibody coupled to PE (1/200; Chemicon, Billerica, MA, USA). Cells were mounted onto cover slips using ProLong Gold antifade with DAPI (Invitrogen) and imaged using a Leica TCS SP2 SE laser scanning confocal microscope using a $63 \times 1$.2water immersion objective. All images were analyzed using Leica software (Allendale, NJ, USA) and were independently repeated a minimum of three times.

Analysis of cell clonogenicity and viability. Clonogenic assays were performed as previously described. ${ }^{31}$ Cell viability was determined by staining cells with FITCcoupled annexin $\mathrm{V}$ (Roche) in balanced salt solution including $5 \mathrm{mM} \mathrm{CaCl}_{2}$ and $\mathrm{PI}$ $(5 \mu \mathrm{g} / \mathrm{ml}$, Sigma) followed by flow cytometric analysis (Becton Dickinson). Viable cells were identified by not binding Annexin V and their ability to exclude PI. All experiments were independently repeated at least three times.

IKK in-vitro kinase assay. Wild-type PUMA or HA-PUMA ${ }^{\text {S10A }}$ were overexpressed in HEK 293T cells overnight before lysis in NP40 lysis buffer. Overexpressed protein was immunoprecipitated from lysates using an antiHA antibody coupled to sepharose beads. The beads were then washed twice in NP40 lysis buffer, washed once in CIP buffer $(50 \mathrm{mM}$ Tris-HCl pH 7.9, $100 \mathrm{mM} \mathrm{NaCl}$, $10 \mathrm{mM} \mathrm{MgCl} 2,1 \mathrm{mM}$ DTT) before being treated with $5 \mathrm{U}$ alkaline phosphatase (Promega, Sydney, NSW, Australia) for $30 \mathrm{~min}$ at $37^{\circ} \mathrm{C}$. Beads were then washed twice with NP40 lysis buffer before being washed once in reaction buffer $(8 \mathrm{mM}$ MOPS/NaOH pH 7.0, $200 \mu \mathrm{M}$ EDTA, $5 \mathrm{mM} \beta$-glycerophosphate). Beads or $1 \mu \mathrm{g}$ recombinant $I_{\kappa} \mathrm{B} \alpha$ were then incubated in an IKK in-vitro kinase assay buffer $(8 \mathrm{mM}$ MOPS/NaOH pH 7.0, $200 \mu \mathrm{M}$ EDTA, $5 \mathrm{mM} \beta$-glycerophosphate, $0.5 \%$ glycerol, $0.001 \%$ Triton X-100, $0.01 \%$ 2-mercaptoethanol, $0.1 \mathrm{mg} / \mathrm{ml} \mathrm{BSA}, 10 \mathrm{mM}$ magnesium acetate, $0.1 \mathrm{mM}$ ATP, $2 \mu \mathrm{Ci}\left[\gamma^{32}{ }^{32}\right.$ ]ATP, $100 \mathrm{ng}$ enzyme (recombinant human IKK1 (US biological, Swampscott, MA, USA)/recombinant human IKK2 (Millipore)) or equivalent volume of reaction buffer. Beads were then washed twice in NP40 lysis buffer, boiled in SDS load buffer before being subjected to SDS-PAGE and western blot analysis to detect protein and exposed to $x$-ray film to detect incorporated ${ }^{32} \mathrm{P}$.

\section{Conflict of Interest}

The authors declare no conflict of interest.

Acknowledgements. We thank David Vaux, Bruce Kemp and Vinay Tergaonkar for helpful comments and reagents. PGE is supported by the Sylvia and Charles Viertel Senior Medical Fellowship. This work was supported by grants from the NHMRC of Australia, the Children's Cancer Centre Foundation, the Cancer Council of South Australia and the Leukaemia Research Fund. JJS is supported by the University of Adelaide divisional PhD scholarship. AMJ is supported by the University of Melbourne Early Researcher Development grant. This work was made possible through Victorian State Government Operational Infrastructure Support and Australian Government NHMRC IRIISS.

1. Yu J, Wang Z, Kinzler KW, Vogelstein B, Zhang L. PUMA mediates the apoptotic response to p53 in colorectal cancer cells. Proc Natl Acad Sci USA 2003; 100: 1931-1936.

2. Villunger A, Michalak EM, Coultas L, Mullauer F, Bock G, Ausserlechner MJ et al. p53- and drug-induced apoptotic responses mediated by $\mathrm{BH} 3-$ only proteins puma and noxa. Science 2003; 302: 1036-1038.

3. Jeffers JR, Parganas E, Lee Y, Yang C, Wang J, Brennan J et al. Puma is an essential mediator of p53-dependent and -independent apoptotic pathways. Cancer Cell 2003; 4: 321-328.

4. Ekoff M, Kaufmann T, Engstrom M, Motoyama N, Villunger A, Jonsson Jl et al. The BH3only protein puma plays an essential role in cytokine deprivation induced apoptosis of mast cells. Blood 2007; 110: 3209-3217. 
5. Zhao Y, Coloff JL, Ferguson EC, Jacobs SR, Cui K, Rathmell JC. Glucose metabolism attenuates p53 and puma-dependent cell death upon growth factor deprivation. $J$ Bio Chem 2008; 283: 36344-36353.

6. Michalak EM, Jansen ES, Happo L, Cragg MS, Tai L, Smyth GK et al. Puma and to a lesser extent noxa are suppressors of Myc-induced lymphomagenesis. Cell Death Differ 2009 16: 684-696.

7. Davidsson J, Lilljebjorn $H$, Andersson $A$, Veerla $S$, Heldrup J, Behrendtz $M$ et al. The DNA methylome of pediatric acute lymphoblastic leukemia. Hum Mol Genet2009; 18: 4054-4065

8. Chen L, Willis SN, Wei A, Smith BJ, Fletcher JI, Hinds MG et al. Differential targeting of prosurvival Bcl-2 proteins by their BH3-only ligands allows complementary apoptotic function. Mol Cell 2005; 17: 393-403.

9. Gallenne T, Gautier F, Oliver L, Hervouet E, Noel B, Hickman JA et al. Bax activation by the $\mathrm{BH} 3$-only protein puma promotes cell dependence on antiapoptotic Bcl-2 family members. J Cell Biol 2009; 185: 279-290.

10. Chipuk JE, Fisher JC, Dillon CP, Kriwacki RW, Kuwana T, Green DR. Mechanism of apoptosis induction by inhibition of the anti-apoptotic BCL-2 proteins. Proc Natl Acad Sci USA 2008; 105: 20327-20332.

11. Ekert PG, Jabbour AM, Manoharan A, Heraud JE, Yu J, Pakusch $M$ et al. Cell death provoked by loss of interleukin-3 signaling is independent of Bad, Bim, and PI3 kinase, but depends in part on Puma. Blood 2006; 108: 1461-1468.

12. Fricker M, O'Prey J, Tolkovsky AM, Ryan KM. Phosphorylation of puma modulates its apoptotic function by regulating protein stability. Cell Death Dis 2010; 1: e59.

13. Jabbour AM, Heraud JE, Daunt CP, Kaufmann T, Sandow J, O'Reilly LA et al. Puma indirectly activates Bax to cause apoptosis in the absence of Bid or Bim. Cell Death Differ 2009; 16: 555-563.

14. Waelchli R, Bollbuck B, Bruns $C$, Buhl T, Eder J, Feifel $R$ et al. Design and preparation of 2-benzamido-pyrimidines as inhibitors of IKK. Bioorg Med Chem Lett 2006; 16: 108-112.

15. Parganas E, Wang D, Stravopodis D, Topham DJ, Marine JC, Teglund S et al. Jak2 is essential for signaling through a variety of cytokine receptors. Cell 1998; 93: 385-395.

16. Nakano K, Vousden KH. PUMA, a novel proapoptotic gene, is induced by p53. Mol Cell 2001; 7: 683-694.

17. Yu J, Zhang L, Hwang PM, Kinzler KW, Vogelstein B. PUMA induces the rapid apoptosis of colorectal cancer cells. Mol Cell 2001; 7: 673-682.

18. Jabbour AM, Daunt CP, Green BD, Vogel S, Gordon L, Lee RS et al. Myeloid progenitor cells lacking p53 exhibit delayed upregulation of puma and prolonged survival after cytokine deprivation. Blood 2010; 115: 344-352.
19. You H, Pellegrini M, Tsuchihara K, Yamamoto K, Hacker G, Erlacher M et al. FOXO3adependent regulation of puma in response to cytokine/growth factor withdrawal. J Exp Med 2006; 203: 1657-1663.

20. Wu WS, Heinrichs S, Xu D, Garrison SP, Zambetti GP, Adams JM et al. Slug antagonizes p53-mediated apoptosis of hematopoietic progenitors by repressing puma. Cell 2005; 123: 641-653.

21. Han J, Flemington C, Houghton AB, Gu Z, Zambetti GP, Lutz RJ et al. Expression of bbc3, a pro-apoptotic $\mathrm{BH} 3$-only gene, is regulated by diverse cell death and survival signals. Proc Natl Acad Sci USA 2001; 98: 11318-11323.

22. del Peso L, Gonzalez-Garcia M, Page C, Herrera R, Nunez G. Interleukin-3induced phosphorylation of BAD through the protein kinase Akt. Science 1997; 278: 687-689.

23. Zha J, Harada H, Yang E, Jockel J, Korsmeyer SJ. Serine phosphorylation of death agonist $B A D$ in response to survival factor results in binding to 14-3-3 not BCL-X(L). Cell 1996; 87: 619-628.

24. Tan Y, Demeter MR, Ruan H, Comb MJ. BAD Ser-155 phosphorylation regulates BAD/ Bcl-XL interaction and cell survival. J Biol Chem 2000; 275: 25865-25869.

25. Hubner A, Barrett T, Flavell RA, Davis RJ. Multisite phosphorylation regulates Bim stability and apoptotic activity. Mol Cell 2008; 30: 415-425

26. Perkins ND. Integrating cell-signalling pathways with NF-kappaB and IKK function. Nat Rev Mol Cell Biol 2007; 8: 49-62.

27. Ebner K, Bandion A, Binder BR, de Martin R, Schmid JA. GMCSF activates NF-kappaB via direct interaction of the GMCSF receptor with IkappaB kinase beta. Blood 2003; 102: 192-199.

28. Perugini M, Brown AL, Salerno DG, Booker GW, Stojkoski C, Hercus TRD et al. Alternative modes of GM-CSF receptor activation revealed using activated mutants of the common |\{betal\}-subunit. Blood 2010; 115: 3346-3353

29. Hercus TR, Thomas D, Guthridge MA, Ekert PG, King-Scott J, Parker MW et al. The GMCSF receptor: linking its structure to cell signaling and its role in disease. Blood 2009; 114: 1289-1298.

30. Leis $\mathrm{H}$, Sanchis A, Perez P. Deletion of the N-terminus of IKKgamma induces apoptosis in keratinocytes and impairs the AKT/PTEN signaling pathway. Exp Cell Res 2007; 313: 742-752.

31. Ekert PG, Read SH, Silke J, Marsden VS, Kaufmann H, Hawkins CJ et al. Apaf-1 and caspase- 9 accelerate apoptosis, but do not determine whether factor-deprived or drugtreated cells die. J Cell Biol 2004; 165: 835-842.

Supplementary Information accompanies the paper on Cell Death and Differentiation website (http://www.nature.com/cdd) 